\title{
Extraction of Cu(II) Ions in Wastewaters Using New Solid/Liquid Phase Microextraction Technique Based on Incorporating Functionalized Carbon Nanotubes into Polypropylene Hollow Fiber
}

\author{
Es'haghi Zarrin $^{1}$, Ahmadpour Ali2 ${ }^{2}$ Tanha Ali Akbar'1, Sayfi Ali1 ${ }^{1}$, Ayati Ali ${ }^{2}$ \\ ${ }^{1}$ Department of Chemistry, Payame Noor University, Tehran, Iran \\ ${ }^{2}$ Department of Chemical Engineering, Ferdowsi University of Mashhad, Mashhad, Iran \\ Email: ${ }^{*}$ eshaghi@pnu.ac.ir
}

Received 21 February 2014; revised 16 April 2014; accepted 2 May 2014

Copyright (C) 2014 by authors and OALib.

This work is licensed under the Creative Commons Attribution International License (CC BY).

http://creativecommons.org/licenses/by/4.0/

\section{(c) (i) Open Access}

\section{Abstract}

This research describes a new design of hollow fiber solid-liquid phase microextraction (HFSLPME) which was developed for the extraction and measurement of $\mathrm{Cu}$ (II) ion in water samples combined with atomic absorption spectroscopy. This method consists of an aqueous feed and the functionalized multi-walled carbon nanotubes (F-MWCNTs) with $\mathrm{HNO}_{3}$ and $\mathrm{NaClO}$, dispersed into n-octanol, are held within the pores and the lumen of a porous hollow fiber as the extractor phase. The presented method allows an effective and enriched recuperation of ionic analyte into MWCNTs/organic phase. The effective parameters were investigated. Under the optimized conditions, a sample of industrial waste water was successfully purified using the proposed method. Our results showed that at optimized extraction conditions, the calibration curve was linear in the range of $0.01-20 \mu \mathrm{g} / \mathrm{mL}$ of $\mathrm{Cu}(\mathrm{II})$ ions in the initial solution with $\mathrm{R}^{2}>0.99$ for both F-MWCNTs samples. All experiments were carried out at room temperature $\left(25^{\circ} \mathrm{C} \pm 0.5^{\circ} \mathrm{C}\right)$.

\section{Keywords}

Solid/Liquid Phase Microextraction, Multi-Walled Carbon Nanotube, Hollow Fiber, Cu(II), Flame Atomic Absorption Spectroscopy

\footnotetext{
${ }^{*}$ Corresponding author.
}

How to cite this paper: Zarrin, E., et al. (2014) Extraction of Cu(II) lons in Wastewaters Using New Solid/Liquid Phase Microextraction Technique Based on Incorporating Functionalized Carbon Nanotubes into Polypropylene Hollow Fiber. Open Access Library Journal, 1: e380. http://dx.doi.org/10.4236/oalib.1100380 


\section{Introduction}

The disposal of industrial effluents that contain heavy metals into natural water systems is a serious worldwide environmental concern. Heavy metals are non degradable and can enter into the food chain by accumulation in animals and plants, so it is necessary to determine and remove them from the waste water before releasing into the environment. There are various approaches that have been used for determination and removing of trace heavy metals, such as precipitation [1], electrochemical treatment, chemical oxidation or reduction, solvent extraction, ion exchange [2], and adsorption [3]. Conventional solid-phase extraction (SPE) and liquid-liquid extraction (LLE) have been widely used for the extraction of metal ions from water samples [4] [5]. It is well known, however, that these methods are time consuming, tedious, often require large amounts of high purity solvent, and can be relatively expensive. To overcome these drawbacks, new simple and rapid sample preparation techniques have been developed over the last two decades including liquid phase microextraction (LPME) [6] and solid-phase microextraction (SPME) [7].

Liquid-phase microextraction or solvent microextraction was developed as a fast, simple and inexpensive solvent-minimized liquid-liquid extraction (LLE) technique [8] [9]. Recently, hollow-fiber liquid-phase microextraction (HF-LPME), based on the application of a supported liquid membrane, was introduced using a porous hollow-fiber membrane [5] [10] in order to improve solvent stability. According to this method, a porous polypropylene hollow fiber impregnated with an organic solvent is used as an acceptor phase [11]. In HF-LPME technique, the organic solvent is injected into and contained within the lumen of the porous hollow fiber as an interface between the sample solution and the extracting phase (the phase into which the analyte is extracted) [12]. Since very little solvent is used, exposure of operator to toxic organic solvents is minimized. At the same time, the technique combines extraction, concentration and sample introduction into one step.

The HF-LPME has been successfully applied for determination and extraction of wide range of targeted analytes [13]-[16]. In fact, the recently introduced method proved to be an attractive alternative to other microextraction concepts having the advantages of being simple, inexpensive, sensitive, fast and virtually solvent-free. In addition, the disposable nature of the hollow fiber, due to the low cost of analysis per sample, eliminates the possibility of carry-over between analyses.

Nowadays, in the solid phase extraction studies of transition metals at trace level, investigation of the usage of new materials, as solid phase extractor is an important challenge [17]. Carbon nanotubes (CNTs) have been proposed as a novel solid phase extractor for various inorganic and organic materials at trace levels. They are relatively new adsorbents for trace pollutants from water, because they have a large specific surface area and small, hollow, and layered structures. Also, CNTs have been proven to possess great potential as superior adsorbents for removing many kinds of organic and inorganic pollutants such as dioxin, volatile organic compounds (VOCs) and fluoride from air stream [18], soil organic matters and various divalent metal ions $\left(\mathrm{Cd}^{2+}\right.$, $\mathrm{Cu}^{2+}, \mathrm{Ni}^{2+}, \mathrm{Pb}^{2+}, \mathrm{Zn}^{2+}$ ) from aqueous solution [19]. The properties of CNTs result in enhancing the efficiency of extraction process.

In the present study, we have developed a new microextraction method for $\mathrm{Cu}(\mathrm{II})$ ions using a combinational solid/liquid phase microextraction (SLPME) technique based on functionalized multi-walled carbon nanotubes (F-MWCNTs) by $\mathrm{HNO}_{3}$ and $\mathrm{NaClO}$ incorporating into hollow fiber. To date, and to the best of our knowledge, no report has been published on the determination and extraction of copper ion in water samples using this method by flame atomic absorption spectroscopy (FAAS). We have investigated the effect of several parameters such as solvent solution, $\mathrm{pH}$, donor phase volume, extraction time, surfactant concentration, and stirring speed on the extraction efficiency and found the optimum experimental condition. Also, at this optimum condition, calibration curve equation and analytical performance parameters were determined. Moreover, the method was tested for the analysis of an industrial wastewater as a real sample analysis.

\section{Experimental Procedure}

\subsection{Chemicals and Apparatus}

Acetone, 1-octanol, hexane, toluene (HPLC grade) and all salts, acids and bases (analytical grade) were purchased from Merck Company (Darmstadt, Germany) and used as received. $\mathrm{Cu}\left(\mathrm{NO}_{3}\right)_{2} \cdot 3 \mathrm{H}_{2} \mathrm{O}$ was obtained from Fluka (Buchs, Switzerland). All the solutions used in this work were prepared by de-ionized water (DI). Analytical $\mathrm{Cu}\left(\mathrm{NO}_{3}\right)_{2} \cdot 3 \mathrm{H}_{2} \mathrm{O}$ was employed to prepare stock solution containing $100 \mu \mathrm{g} / \mathrm{mL}$ of $\mathrm{Cu}(\mathrm{II})$, which was fur- 
ther diluted with DI water to the desired Cu(II) concentrations. The use of DI water was to prevent the effect of solution ionic strength.

The hollow fiber polypropylene membrane, $\mathrm{Q}_{3 / 2}$ Accurel PP (200 $\mu \mathrm{m}$ thick wall, $600 \mu \mathrm{m}$ inner diameter and $0.2 \mu \mathrm{m}$ average pore size) was purchased from Membrana (Wuppertal, Germany). Their SEM images are shown in Figure 1. The multi-walled carbon nanotubes (MWCNTs) were obtained from the Research Institute of Petroleum Industry (Tehran, Iran) with mean diameter of $10-15 \mathrm{~nm}$, length of $50-100 \mathrm{~nm}$, and purity > 98\%.

The concentration of $\mathrm{Cu}(\mathrm{II})$ was determined by a flame atomic absorption spectrometer (FAAS), Model PU9600 X instrument, with Cu Lamp, $8 \mathrm{~mA}$ current, $324.8 \mathrm{~nm}$ wavelength; $0.5 \mathrm{~nm}$ band pass, standard type burner head, $5 \mathrm{~mm}$ burner height, air-acetylene flame, 1.25 bar oxidant gas pressure, and $2 \mathrm{~L} / \mathrm{min}$ fuel gas flow rate.

The functional groups of CNTs were identified by Fourier Transform Infrared spectroscopy (FTIR) analysis (SHIMADZU-8400, Japan) and the size and morphology of CNTs and hollow fibers were observed by Scanning Electron Microscopy (SEM) using a GXA840 model.

\subsection{Functionalization of MWCNTs}

The metal ion sorption capacity of F-MWCNTs does not have a direct correlation with their specific surface area, pore specific volume and mean pore diameter, but strongly depends upon their surface total acidity. The metal ion sorption capacity of CNTs increased as a rise in the amount of surface total acidity (including carboxyls, lactones and phenols) present on the surface site of CNTs. This reflects that the sorption of metal ions onto CNTs is a chemisorption process rather than physic-sorption. The oxidized CNTs have more total active surface, which are responsible for sorption of $\mathrm{Cu}(\mathrm{II})$ ions from aqueous solution, than the raw CNTs. The mechanisms by which the metal ions are adsorbed onto CNTs are very complicated and appear attributable to electrostatic attraction, sorption-precipitation and chemical interaction between the metal ions and the surface functional groups of CNTs.

The chemical interaction between the metal ions and the surface functional groups of CNTs is the major sorption mechanism [20] [21]. Protons in the carboxylic and phenolic groups of CNTs exchange with the metal ions in the aqueous phase. The solution $\mathrm{pH}$ dropped after sorption of metal ion onto CNTs and reached equilibrium, which could be explained by the release of $\mathrm{H}^{+}$from the CNT surface into the solution.

We used two methods for surface modification of purchased MWCNTs by $\mathrm{HNO}_{3}$ and $\mathrm{NaOCl}$ to remove any metal catalysts and amorphous carbon. In the first one, raw CNTs were functionalized with acid according to the following procedure. MWCNTs were dispersed into a flask containing concentrated $\mathrm{HNO}_{3}$ solution and then refluxed for $6 \mathrm{~h}$ at $140^{\circ} \mathrm{C}$ to remove the impurity and modify the surface functionality. After cooling, the F-MWCNTs were washed with deionized water repeatedly, until the $\mathrm{pH}$ of the solution reached approximately 7. Then, the solution was filtered and the functionalized nanotubes dried in the oven for $4 \mathrm{~h}$ at $120^{\circ} \mathrm{C}$.

In the second method, the MWCNTs $(3 \mathrm{~g})$ were heated at $350^{\circ} \mathrm{C}$ for 30 min to remove amorphous carbon. After thermal treatment, $0.5 \mathrm{~g}$ of CNTs was dispersed into a flask containing $20 \mathrm{~mL}$ of $70 \%$ sodium hypochlo-

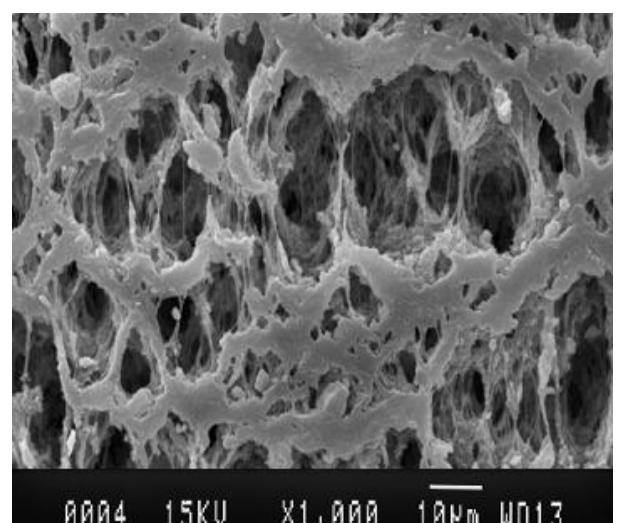

(a)

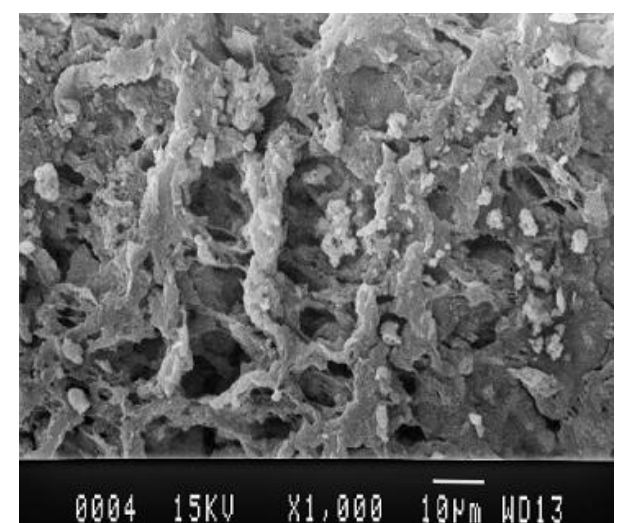

(b)

Figure 1. SEM images of a polypropylene hollow fiber (a) before and (b) after filling with functionalized MWCNTs in 1-Octanol. 
rite solution. Then, the solution was shaken in an ultrasonic bath for 20 min. Next, they were continuously stirred for $3 \mathrm{~h}$ at $85^{\circ} \mathrm{C}$ to remove metal catalyst. After cooling, the modified CNTs were washed frequently using deionized water until the $\mathrm{pH}$ of solution reached about 7 . Finally, the solution was filtered through a $0.45 \mathrm{~m} \mathrm{Ny}-$ lon fiber filter and purified functionalized-MWCNTs (F-MWCNTs) were obtained. The modified CNTs were dried at $80^{\circ} \mathrm{C}$ for $12 \mathrm{~h} \mathrm{[22].}$

In these cases, the carboxylic MWCNTs formed a network like a polymer and afforded the additional interactions for the analyte molecules. The treated MWCNTs were terminated with carboxylic acid and hydroxyl groups (See Figure 2). The non-treated MWCNTs aggregated in a disorderly fashion, but the functionalized MWCNT, in contrast, was well dispersed because of the presence of the functional groups that repel each other electrostatically. Therefore, the treated MWCNTs were selected as the raw material for the subsequent microextraction procedure.

\subsection{HF-SLPME Procedure}

The membrane extraction with sorbent interface used in this research is a two phase microextraction consisting of aqueous feed and organic solvent/nano sorbent extracting phases. The second phase was supported by a piece of polypropylene hollow fiber and the system operated in direct immersion sampling modes. F-MWCNTs was dispersed in the organic solvent and held in the pores and lumen of a porous membrane supported by capillary forces and sonication. The analytes diffuse from the aqueous sample through the pores and inside of polypropylene membrane into F-MWCNTs dispersing in the organics solvent. As the organic solvent immobilized in the pores, the analyte was then snared in a sorbent (micro) trap and thus enriched.

All microextraction experiments were performed using an Accurel $Q_{3 / 2}$ polypropylene hollow fiber membrane (600 $\mu \mathrm{m}$ I.D., $200 \mu \mathrm{m}$ wall thicknesses, $0.2 \mu \mathrm{m}$ pore size). The fiber was cut into small segments with a length of $2.5 \mathrm{~cm}$ and $15 \mu \mathrm{L}$ of a dispersed mixture of the F-MWCNTs in 1-Octanol was gradually injected into the fiber manually using a micro-syringe $(25 \mu \mathrm{L})$. The pores and the fiber duct were filled with the homogenized mixture and excess amount of mixture was carefully removed from the inside of the fiber. Then, the fiber was bent as a U-shape and together with a small part of the supporting syringe needle was submerged in the sample $\mathrm{Cu}(\mathrm{II})$ solution present in a proper vial according to the donor phase volume. The vial was covered and stirred at $600 \mathrm{rpm}$ for $30 \mathrm{~min}$ [23].

After the extraction, fiber transferred into a small glass vial. The fiber and the pores were sonicated with $2 \mathrm{~mL}$

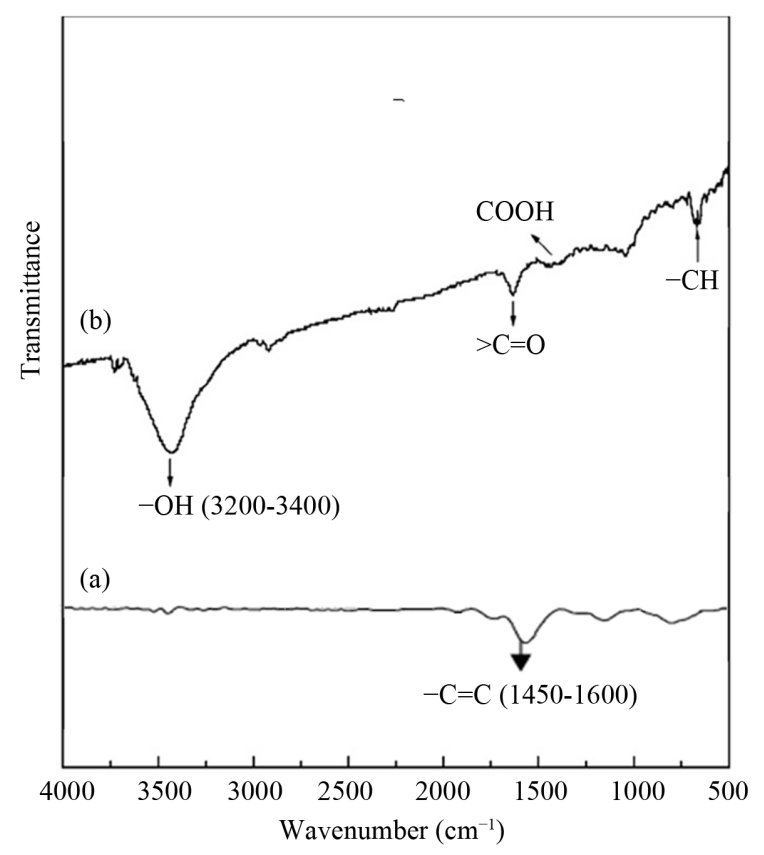

Figure 2. FT-IR spectrum of raw and functionalized MWCNTs. 
of solution containing $50 \%$ of $\mathrm{HCl}(0.1 \mathrm{M})$ and methanol which was collected in the small vial. Then, $\mathrm{Cu}(\mathrm{II})$ concentration was determined in the concentrated phase using atomic absorption spectrophotometer.

The Octanol/F-MWCNTs was immiscible with water and remained within the fiber pores during extraction with no leakage to the aqueous sample. The organic solvent/CNT formed a thin layer within the wall of the hollow fiber, which on average had a thickness of $200 \mu \mathrm{m}$, and the total volume of organic solvent immobilized was typically 15 - $20 \mu \mathrm{L}$. For metal ions, with addition of proper ligand or ion pair, the ions are converted to deionized form to reduce their solubility within the aqueous sample and also organic phase (See Figure 3).

\subsection{Extraction Process}

The analytes are extracted from the aqueous sample, through the organic phase/MWCNTs in the pores of the hollow fiber, and further into an acceptor solution inside the lumen of the hollow fiber. In two-phase LPME, analytes are extracted by passive diffusion from the aqueous sample (donor solution) directly into the organic phase/MWCNTs. This process is described by Equation (1).

$$
\text { A(Sample) } \leftrightarrow \text { A(Organic phase/MWCNTs) }
$$

The extraction process depends on the partition coefficient between the acceptor phase and the donor solution $\left(K_{a} / d\right)$ defined by Equation (2).

$$
K_{a} / d-C_{e, p, a} / C_{e, p, d}
$$

where $C_{e, p, a}$ and $C_{e, p, d}$ are analyte concentration at equilibrium in the acceptor and donor solution, respectively. Also, the extraction recovery, $R$, and the enrichment factor, $E F$, in the two-phase LPME system may be calculated by the following equations [24] [25]:

$$
\begin{gathered}
R=\left(100 K_{a} / d \cdot V_{a}\right) /\left(K_{a} / d \cdot V_{a}+V_{d}\right) \\
E F=\left(V_{d} \cdot R\right) /\left(V_{a} \cdot 100\right)
\end{gathered}
$$

where $V_{a}$ is the volume of acceptor solution(nano-particle's volume can be concidered negligible in compare to solvent volume) and $V_{d}$ is the volume of donor solution. All experiments were performed in triplicate and their average was used in calculations.

\section{Results and Discussion}

There are several parameters that affect the effectiveness of the used method, such as MWCNTs content, $\mathrm{pH}$,

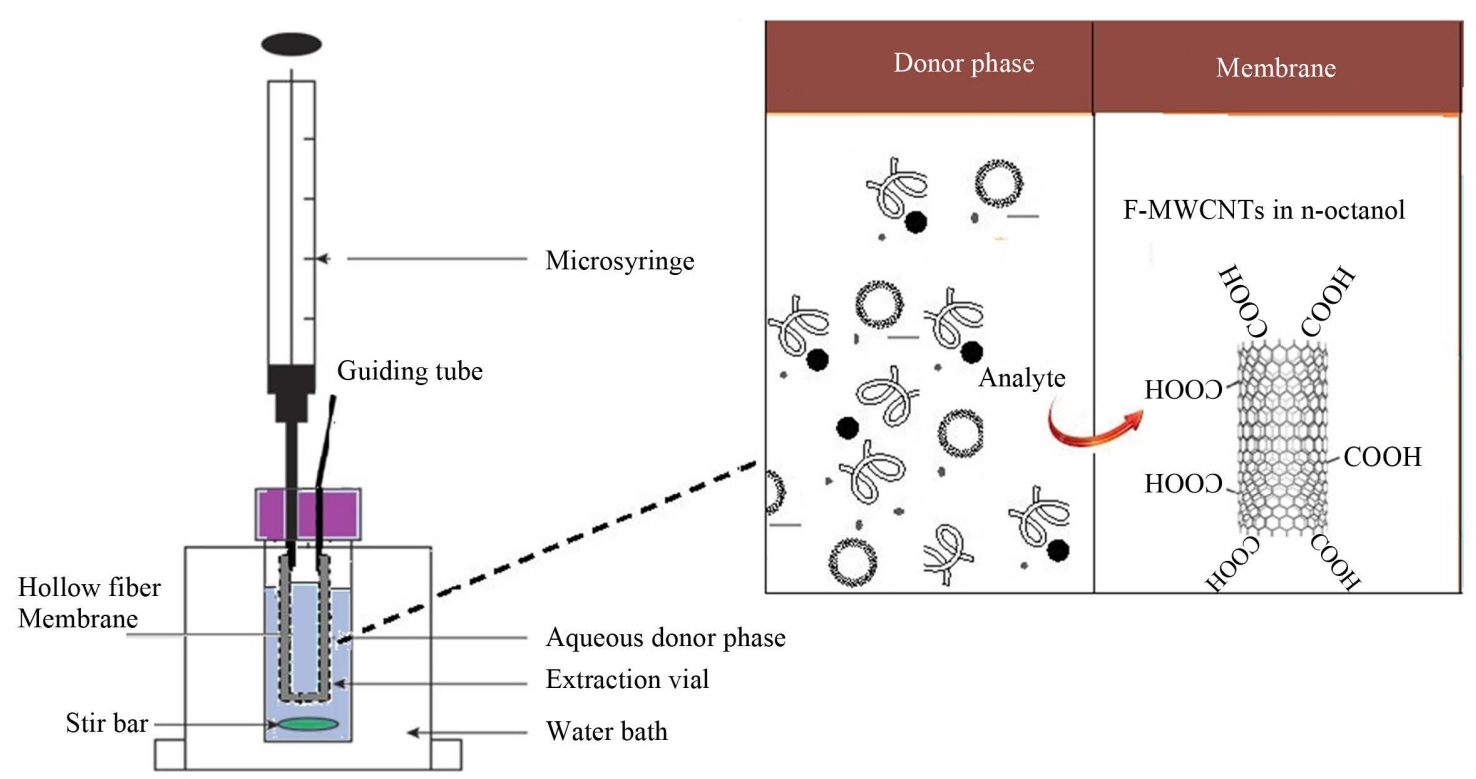

Figure 3. Schematic diagram for the HF-SLPME method. 
donor phase volume, time and etc. In order to obtain high enrichment and extraction efficiency of the analyte using this technique, the main parameters were optimized.

\subsection{Organic Solvent}

The MWCNTs must be well dispersed in the organic solvent. On the other hand, CNTs are insoluble in all solvents due to the large inter-tube attraction energy [26] [27] and therefore agglomerated in the organic solvents. One approach is the functionalization of the surface of CNTs using covalent chemistry. Thus, the dispersion of CNTs into suitable organic solvent seems very attractive to preserve the extended $\pi$ networks of the CNTs when it is used as modifier for adsorption applications [28]. In this work, with respect to our last research findings, 1-octanol has been selected as the organic solvent [29] [30]. Moreover, CNTs diameter is large enough to easily accommodate octanol molecules; however, the octanol-octanol hydrogen-bond breakage for transitioning an octanol molecule to the interior of the nanotube will be much smaller than for water. It is reasonable to expect that since the nanotube is wide enough to accommodate many octanol molecules, this effect is also due to solvent molecules entering the cavity of the nanotube and hydrogen bonds being broken resulting in a higher energy.

\subsection{Effect of F-MWCNTs Content}

In this study, the effect of F-MWCNTs content as one of the most important factors which can affect the extraction efficiency of $\mathrm{Cu}(\mathrm{II})$, was investigated. For this purpose, $0.15 \mathrm{~g}$ of F-MWCNTs was dispersed into flasks containing 4, 5.5, and $7 \mathrm{~mL}$ of 1-Octanol and was shaken in an ultrasonic cleaning bath for $10 \mathrm{~min}$. Then, $15 \mu \mathrm{L}$ of each dispersed mixture was gradually injected into the fiber manually using a microsyringe. For volumes less than $4 \mathrm{~mL}$, we could not inject the dispersed mixture into the fibers, because of high concentrations of FMWCNTs. Results of enrichment factor versus amounts of MWCNTs are shown in Figure 4.

As seen in the figure, increasing the amount of MWCNTs enhances the adsorption of $\mathrm{Cu}(\mathrm{II})$ on the CNTs surface and consequently improve the extraction efficiency. Although the extraction efficiency was increased, but for values more than $0.056 \mathrm{~g}$ CNTs per $2.5 \mathrm{~cm}$ fiber segment, the injection of mixture into hollow fiber was very difficult. Therefore, we have selected $0.056 \mathrm{~g}$ of MWCNTs per $2.5 \mathrm{~cm}$ hollow fiber for the rest of experiments.

\subsection{Effect of pH}

$\mathrm{pH}$ is an important analytical parameter because it has an strong effect on the adsorption characteristics of $\mathrm{Cu}(\mathrm{II})$ onto MWCNTs and enlargement of extraction efficiency. The effect of $\mathrm{pH}$ in the donor phase on the enrichment factor was studied in the range of 3.0 - 8.0. The copper species are presented in the DI water in various forms, but at $\mathrm{pH}<8$ the predominant form is always $\mathrm{Cu}^{2+}$ and its removal is mainly accomplished by extraction process. The results presented in Figure 4 indicate that the maximum enrichment factors are in $\mathrm{pH} 4$ and 5 for MWCNTs functionalized with $\mathrm{NaClO}$ and $\mathrm{HNO}_{3}$, respectively. Therefore, for both types of F-MWCNTs, low $\mathrm{Cu}(\mathrm{II})$ adsorption and extraction efficiency take place at low $\mathrm{pH}$ that can be attributed in part to competition between $\mathrm{H}^{+}$ and $\mathrm{Cu}^{2+}$ ions on the same sites of CNTs (See Figure 5).

\subsection{Effect of Donor Phase Volume}

As the analyte is extracted from relatively large sample volumes into a very small volume of acceptor solution, microextraction method provide substantial analyte enrichment. The enrichment in LPME is basically determined by the analyte recovery and also by the sample volume. When volume of the sample increases, the enrichment factor also increases (Equation (4)) [13] [31]. In HF-SLPME, the extraction is an equilibration process that causes the amount of analyte partitioning into the acceptor solution and it is independent of the sample volume when this volume is much higher than the product of the partition constant and the volume of the acceptor solution [31]. Moreover, a large sample volume can even be disadvantageous due to poorer mass transfers kinetics, resulting in a worse extraction efficiency.

We have optimized the effect of donor phase volume by changing the volume of the donor phase between 6.0 to $10.0 \mathrm{~mL}$, while the volume of acceptor phase was kept constant at (See Figure 6). The enrichment factor increases by increasing the donor phase to $7 \mathrm{~mL}$. But, at above $7 \mathrm{~mL}$, the enrichment factor exhibited contrary trend. Finally, optimum donor phase volume was selected as $7.0 \mathrm{~mL}$ for both types of F-MWCNTs. 


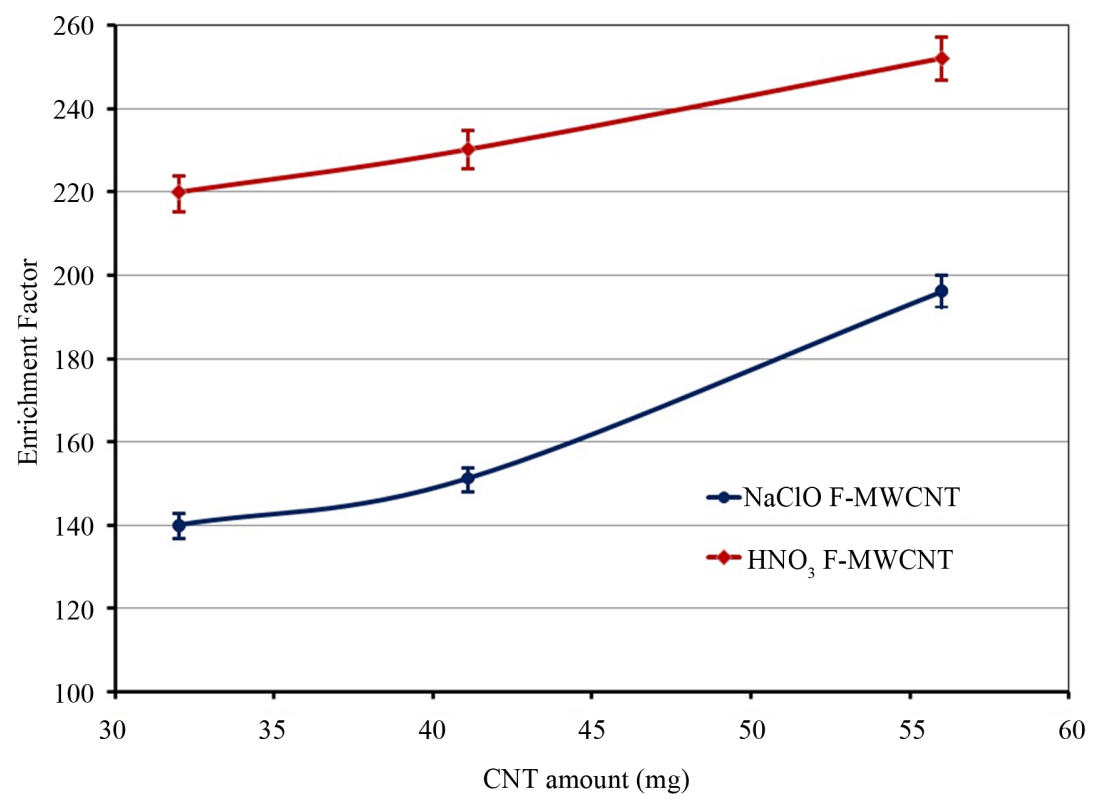

Figure 4. Effect of F-MWCNTs amount on enrichment factor, Experimental conditions are: $\left[\mathrm{Cu}^{2+}\right] 5 \mu \mathrm{g} / \mathrm{mL}$, donor phase volume $8 \mathrm{~mL}, \mathrm{pH}$ 5.7, stirring speed $800 \mathrm{rpm}$, extraction time $30 \mathrm{~min}$.

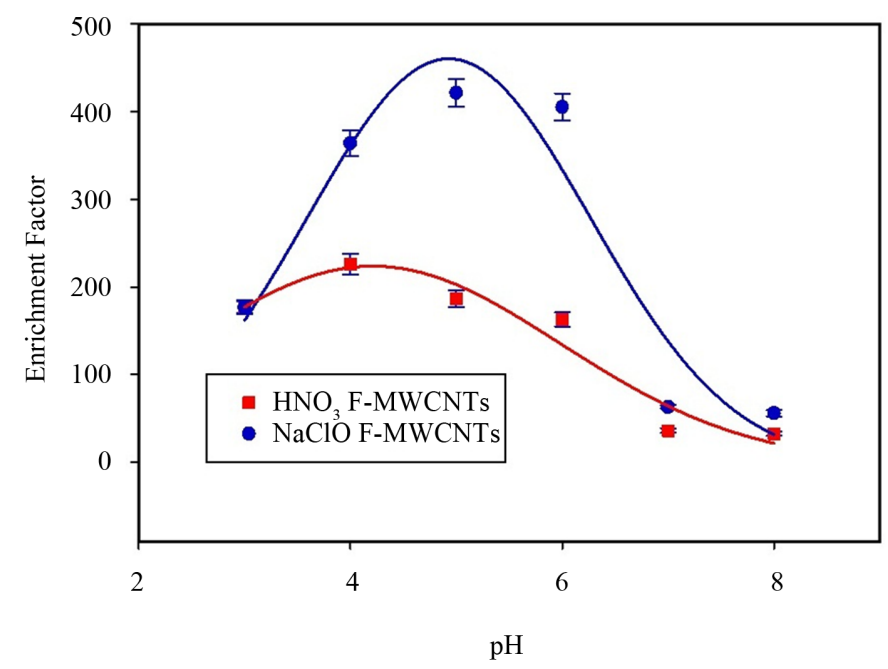

Figure 5. Effect of pH on the enrichment factor for two kinds of FMWCNTs as sorbents. Experimental conditions are: $\left[\mathrm{Cu}^{2+}\right] 5 \mu \mathrm{g} / \mathrm{mL}$, $\mathrm{pH} 4$, donor phase volume; $7 \mathrm{~mL}$, stirring speed $800 \mathrm{rpm}$, extraction time $30 \mathrm{~min}$.

\subsection{Effect of Extraction Time}

The extraction time is a very important parameter in an SLPME procedure, because it influences the partition of the target analytes between the sample solution and the membrane (in the pores of the fiber) and subsequently between the organic solvent and the acceptor phase in the lumen of the fiber. In fact, the longer equilibration times do not have any significant effect on the microextraction efficiency [32].

Different extraction times were tested and the corresponding results are provided in Figure 7. The results demonstrated that the extraction efficiency gradually increased with the extraction time to $75 \mathrm{~min}$ for both types of F-MWCNTs, but did not reach equilibrium. 


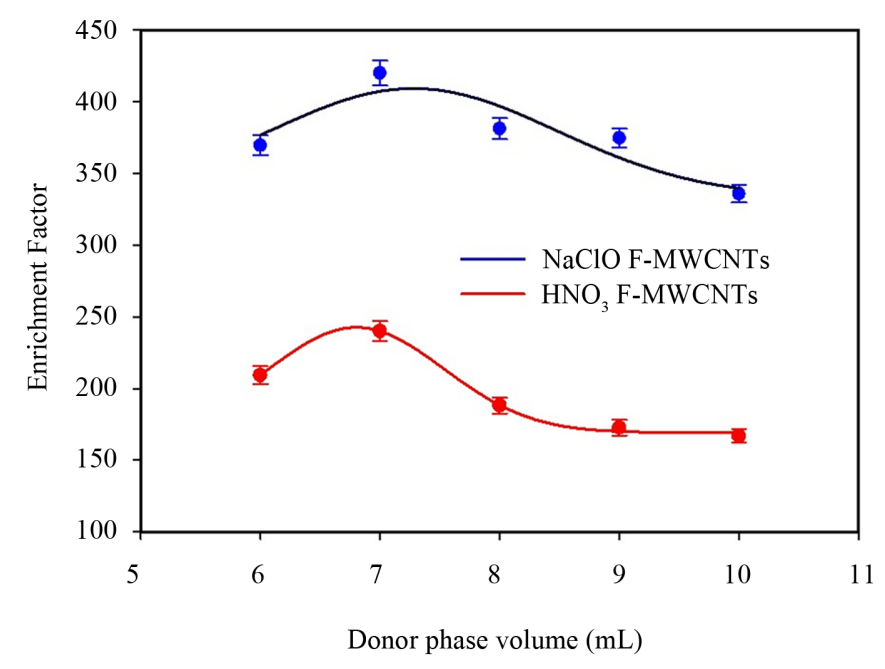

Figure 6. Effect of donor phase volume on the $\mathrm{Cu}(\mathrm{II})$ extraction after HF-SLPME, Experimental conditions are: $\left[\mathrm{Cu}^{2+}\right] ; 5 \mu \mathrm{g} / \mathrm{mL}, \mathrm{pH}$ 4 (for $\mathrm{HNO}_{3}$ F-MWCNTs) and 5 (for NaClO F-MWCNTs), stirring speed $800 \mathrm{rpm}$, extraction time $30 \mathrm{~min}$.

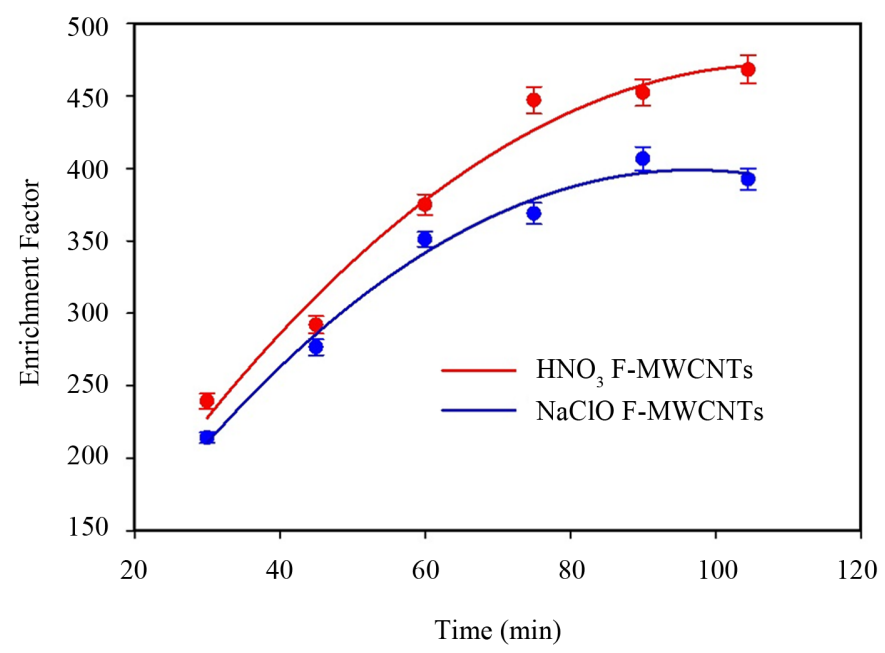

Figure 7. Effect of time on enrichment factor. Experimental conditions are: $\left[\mathrm{Cu}^{2+}\right] 5 \mu \mathrm{g} / \mathrm{mL}$, donor phase volume $7 \mathrm{~mL}, \mathrm{pH} 4$ (for $\mathrm{HNO}_{3} \mathrm{~F}-\mathrm{MWCNTs}$ ) and 5 (for NaClO F-MWCNTs), stirring speed $800 \mathrm{rpm}$.

MWCNTs are a porous layer, in which mass transfer is a process of diffusion through the pores. Therefore, the porosity should strongly affect the extraction dynamics. These nanometer pores of MWCNTs might lead to longer equilibrium time for the extraction of the analytes compared with the conventional HF-LPME mode.

Although SLPME is not an exhaustive extraction technique, maximum sensitivity is attained at equilibrium conditions. It is not necessary for a routine analysis to reach complete equilibrium as long as the extraction time is kept constant. Therefore, 60 min was chosen as the extraction time based on the consideration of sensitivity and analysis speed.

\subsection{Effect of Surfactant Concentration}

Surfactants can be added to the solution to better disperse the nanotubes and prevent their re-aggregation. A selection of appropriate surfactant is fundamental for obtaining a satisfactory pre-concentration and also an extrac- 
tion process. An especially consideration should be given to interaction of surfactant with the analyte and matrix as well as the solubility of the analyte [33]. The anionic surfactants can be good choices for extracting the cations such as $\mathrm{Cu}(\mathrm{II})$. Moreover, ionic surfactants are water soluble. So, we have used Sodium Lauryl Sulfate $\left(\mathrm{C}_{12} \mathrm{H}_{25} \mathrm{SO}_{4} \mathrm{Na}\right.$, SLS $)$ as an anionic surfactant that is used in many cleaning and hygiene products.

On the other hand, we should investigate the surfactant concentration as an important parameter for effective extraction. Concentration of SLS was studied in the range of 5 to $8 \mathrm{mM}$, below the critical micelle concentration (CMC) which is $8.3 \mathrm{mM}$ [34]. Our observations have shown that, when the surfactant concentration in the donor solution was reached over its CMC, the extraction efficiency decreased sharply. It is due to great trapping of $\mathrm{Cu}(\mathrm{II})$ with micelles. In fact, at concentration higher than CMC, by adding analyte, a fraction of that incorporated into the micelle are trapped within the micelle core and could not passes completely through the hollow fiber pores. Furthermore, high concentration of surfactant results relatively high viscosity which reduces the $\mathrm{Cu}(\mathrm{II})$ ion transformation into the organic phase.

The results of variation of surfactant concentration on the enrichment are shown in Figure 8. It is seen that increasing the surfactant concentration to $7 \mathrm{mM}$ leads to increase the enrichment factor and the optimized concentration of $7 \mathrm{mM}$ is the best concentration for $\mathrm{Cu}(\mathrm{II})$ ions extraction.

\subsection{Effect of Stirring Speed}

Stirring enhances mass transfer and reduces the required time to reach thermodynamic equilibrium [35]. In the SLPME, the hollow fiber protects the acceptor mixture, and consequently high agitation speeds can be applied. The results of our previous study have indicated that SLPME efficiency increases with an increase in agitation speed [28] [36]. In general, increasing the agitation rate of the aqueous sample enhances extraction by aiding diffusion of analyte present in the donor phase through the interfacial layer of the hollow fiber and into the acceptor solution. In this work and in a set of experiments, the effect of sample agitation during extraction was investigated by performing $30 \mathrm{~min}$ extractions on aqueous solutions containing $2 \mathrm{mg} / \mathrm{L}$ of target analyte at stirring rates of 600 to $900 \mathrm{rpm}$. Two different trends were obtained for F-MWCNTs. It can be seen in Figure 9 that, in the case of F-MWCNTs with $\mathrm{HNO}_{3}$, increasing the agitation rate resulted in an increase of the enrichment factor for target analyte. However, after 800 rpm we consider fiber fluctuation. For the F-MWCNTs with NaClO, stirring speed has a similar effect on the extraction efficiency, but up to $700 \mathrm{rpm}$. For the speeds higher than 700 rpm, the results show a contrary trend that led to fiber fluctuations and caused the instability.

Furthermore, due to the formation of air bubbles generated on or near the fiber surface, analyte extraction was decreased. On the basis of the above results, 800 and $700 \mathrm{rpm}$ was used as the optimum stirring speeds for F-MWCNTs with $\mathrm{HNO}_{3}$ and NaClO, respectively.

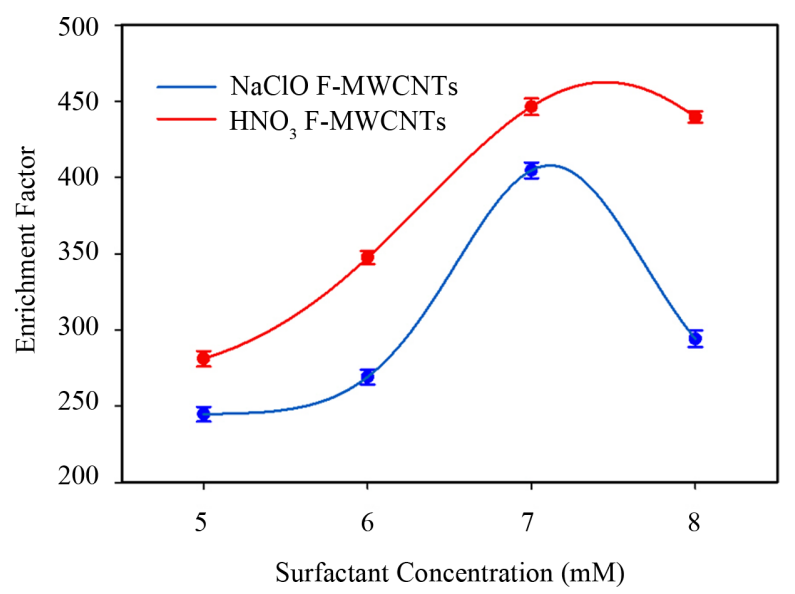

Figure 8. Effcet of surfactant concentration on the enrichment factor. Experimental conditions are: $\left[\mathrm{Cu}^{2+}\right] 5 \mu \mathrm{g} / \mathrm{mL}$, donor phase volume $7 \mathrm{~mL}$, $\mathrm{pH} 4$ (for $\mathrm{HNO}_{3}$ F-MWCNTs) and 5 (for NaClO F-MWCNTs), stirring speed 800 rpm, extraction time $60 \mathrm{~min}$. 


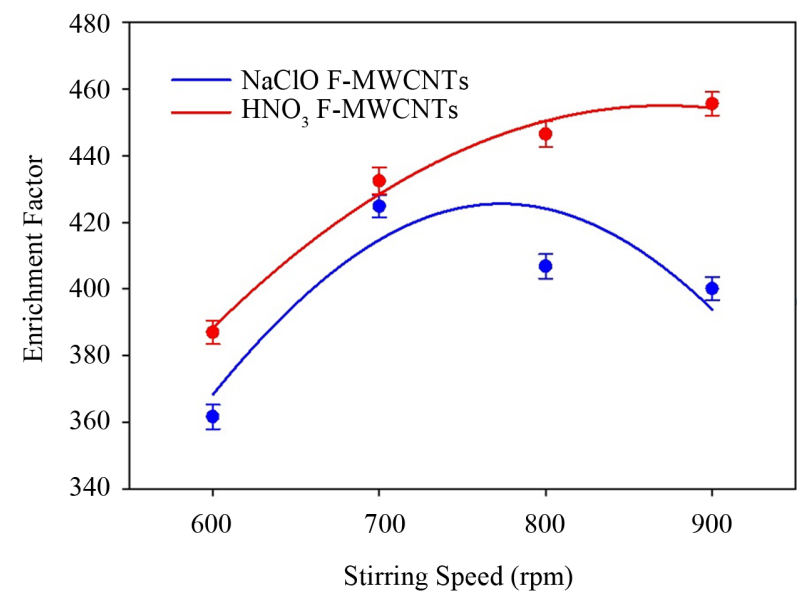

Figure 9. Effect of stirring speed on the extraction efficiency. Experimental conditions are: $\left[\mathrm{Cu}^{2+}\right] 5 \mu \mathrm{g} / \mathrm{mL}$, donor phase volume $7 \mathrm{~mL}$, pH 4 (for $\mathrm{HNO}_{3}$ F-MWCNTs) and 5 (for $\mathrm{NaClO}$ F-MWCNTs), extraction time 60 min.

\subsection{Effect of Salt}

In many conventional extraction processes, the addition of salt improves the extraction efficiency. Because the organic acceptor/aqueous donor phase distribution coefficient can be enhanced by increasing the ionic strength of the aqueous sample [10] [37]. This phenomenon helps to enhance the affinity of the acceptor phase for the analyte molecules. In general, depending on the nature of the target analyte, addition of salt to the sample solution can decrease analyte solubility and consequently increase its hydrophobicity [38]. This is due to the saltingout effect where fewer water molecules are available for dissolving the analyte molecules, preferably forming hydration spheres around the salt ions [39]. Among the salts, sodium chloride $(\mathrm{NaCl})$ is commonly added to analytical samples [10]. In order to examine the effect of ionic strength of the sample matrix upon extraction, a series of experiments were carried out where the aqueous samples contained different amounts of $\mathrm{NaCl}$. So, the effect of increasing $4 \% \mathrm{NaCl}$ was tested (See Figure 10). As seen in the figure, the extraction efficiency is reduced.

This may be due to competitive interaction of $\mathrm{Na}^{+}$with active sites on the F-MWCNTs surface that caused decrease in sorption capacity of $\mathrm{Cu}^{2+}$ ions by CNTs. In addition, the presence of salt caused a second effect; the physical properties of the aqueous-organic solvent extraction film were changed. Therefore, salt was not added to the feed solution.

\subsection{Interfering Effects}

Also, the influence of increased concentration of some cations and anions on the interfering effects of $\mathrm{Cu}(\mathrm{II})$ was determined and is shown in Table 1. Selectivity of the copper ion was investigated and possibility of different metal ions extraction was evaluated for two concentration levels for each interfering ion. As seen, $\mathrm{Cu}(\mathrm{II})$ ion absorption changes in the presence of the ionic species. These changes might be due to competitive adsorption on the CNTs or negative effect of salts.

According the results, $\mathrm{Ca}(\mathrm{II})$ and $\mathrm{Mg}(\mathrm{II})$ showed interference effect on the $\mathrm{Cu}(\mathrm{II})$ detection. Our previous batch laboratory experiments indicated metal ion binding to MWCNTs functional groups was occurred via an ion-exchange type mechanism. The interference observed may be due to the increased concentration of hard ions in solution, instead of competition for binding sites.

However, due to the presence of hard cations such as calcium and magnesium found in contaminated ground waters, interference studies were performed with carboxy functionalized MWCNTS. The ability to bind $\mathrm{Cu}(\mathrm{II})$ ion while being immersed in less than 50 times more concentration of calcium and magnesium indicates that the F-MWCNTS may be selectively binding the heavy metals in solution. Therefore, specific binding sites with chemical functional groups that have higher affinities for heavy metals may be responsible. Only a reduction in copper (II) binding was observed again after 50 times more concentration of calcium and magnesium were 


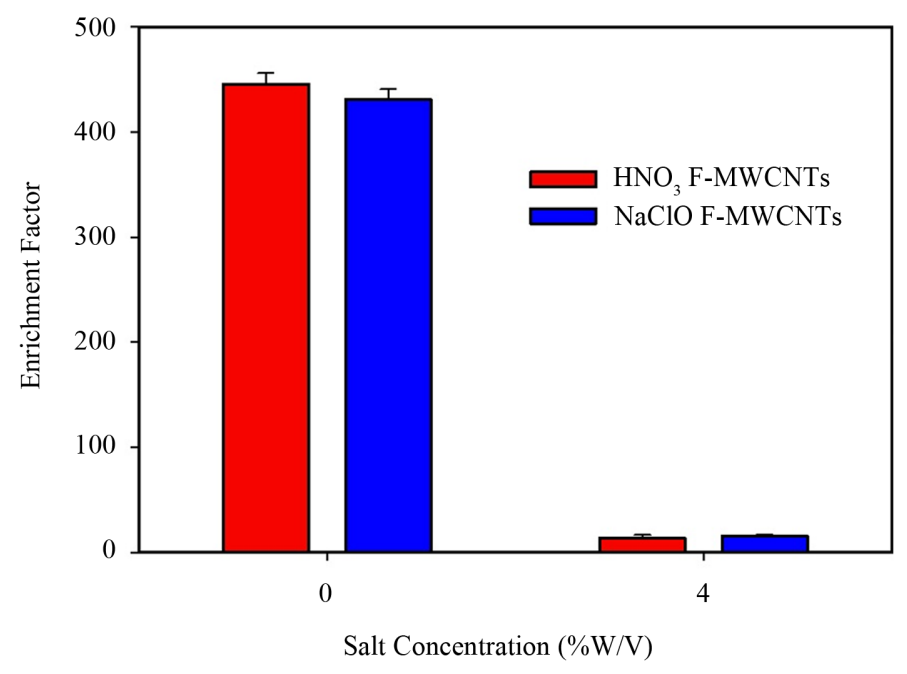

Figure 10. Effect of $\mathrm{NaCl}$ concentration on the enrichment factor in the extraction of $\mathrm{Cu}(\mathrm{II})$. Experimental conditions are: $\left[\mathrm{Cu}^{2+}\right] 5 \mu \mathrm{g} / \mathrm{mL}$, donor phase volume $7 \mathrm{~mL}$, pH 4 (for $\mathrm{HNO}_{3}$ F-MWCNTs) and 5 (for NaClO F-MWCNTs), extraction time $60 \mathrm{~min}$, stirring speed $800 \mathrm{rpm}$ (for $\mathrm{HNO}_{3}$ F-MWCNTs) and 700 (for NaClO F-MWCNTs).

Table 1. Effect of ionic interferences on the $\mathrm{Cu}(\mathrm{II})$ ion microextraction procedure in HF-SLPME.

\begin{tabular}{cccc}
\hline Interfering ions & Interfering ions concentration $(\boldsymbol{\mu g} / \mathbf{m L})$ & $\mathbf{A}^{\mathbf{b}}$ & $\mathbf{A}^{\mathbf{a}}$ \\
\hline $\mathrm{Mg}^{2+}$ & 50 & 0.107 & 0.043 \\
$\mathrm{Mg}^{2+}$ & 500 & 0.107 & 0.011 \\
$\mathrm{Ca}^{2+}$ & 50 & 0.107 & 0.068 \\
$\mathrm{Ca}^{2+}$ & 500 & 0.107 & 0.021 \\
$\mathrm{~K}^{+}$ & 50 & 0.107 & 0.115 \\
$\mathrm{~K}^{+}$ & 500 & 0.107 & 0.100 \\
$\mathrm{Na}^{+}$ & 50 & 0.107 & 0.096 \\
$\mathrm{Na}^{+}$ & 500 & 0.107 & 0.060 \\
$\mathrm{SO}_{4}^{2-}$ & 50 & 0.107 & 0.130 \\
$\mathrm{SO}_{4}^{2-}$ & 500 & 0.107 & 0.082 \\
$\mathrm{Cl}^{-}$ & 50 & 0.107 & 0.086 \\
$\mathrm{Cl}^{-}$ & 500 & 0.107 & 0.093 \\
\hline
\end{tabular}

$\mathrm{A}^{\mathrm{b}}$ : Absorbance of $\mathrm{Cu}(\mathrm{II})$ before adding interfering ions, $\mathrm{A}^{\mathrm{a}}$ : Absorbance of $\mathrm{Cu}(\mathrm{II})$ after adding interfering ions.

added. This overall difference may indicate that it is the quantity of hard cations in solution rather than the identity of the hard ions that plays a role in the reduction of heavy metal binding to F-MWCNTS.

The occurrences of binding specific metal ions in an ion-rich solution might be explained by the binding constants of various functional groups that could be responsible for the heavy metal binding. Thus, the binding constants for various functional groups such as carboxylates groups have an overall higher binding affinity for the $\mathrm{Cu}(\mathrm{II})$ ions rather than calcium and magnesium. Because the binding constants for the heavy metal binding to the various functional groups have higher stability constants, it stands to reason that the metals would bind before the hard cations would. On the other side, total calcium and magnesium could masked with EDTA at pH 10 while the $\mathrm{Cu}(\mathrm{II})$-EDTA chelate is formed in initial $\mathrm{pH}$ of 5.2 . 


\section{Analytical Performance}

From measurements made under the optimum conditions, for both types of F-MWCNTs, the performance parameters of the HF-SLPME technique, such as calibration curve equations, correlation coefficient, liner dynamic range, limits of detection and quantification, and relative standard deviations (RSD\%) were studied. Calibration curve equations were $\mathrm{Y}=0.0434 \mathrm{X}+0.0048$ with $\mathrm{r}^{2}=0.9947$ and $\mathrm{Y}=0.04 \mathrm{X}+0.0052$ with $\mathrm{r}^{2}=0.9977$ for $\mathrm{HNO}_{3}$ and NaClO F-MWCNTs respectively. The calibration graphs were linear in the range of $0.01-20 \mu \mathrm{g} / \mathrm{mL}$ for $\mathrm{HNO}_{3}$ and $\mathrm{NaClO}$ F-MWCNTs with regression coefficients of $\mathrm{r}^{2}=0.9947$ and $0.9977(n=5)$, respectively. The other results are listed in Table 2.

\section{Real Sample Analysis}

To demonstrate the practical applicability of this extraction technique, an industrial wastewater sample from a factory in Mashhad, Iran was taken and analyzed using both types of F-MWCNTs. The results are summarized in Table 3.

\section{Comparison with Other Methods}

The used technique is compatible with a broad range of analytes, including biological and environmental samples and in connection with wide range of analytical instruments such as spectroscopic and chromatographic methods. This compatibility may provide a strong platform for future analytical extractions. Some of methods which were used for determination of $\mathrm{Cu}^{2+}$ in the water samples using FAAS are shown in Table 4.

\section{Conclusions}

A novel, fast and simple procedure based on the non-exhaustive functionalized MWCNTs assisted HF-SLPME equilibrium sampling combined with FAAS has been developed to extract $\mathrm{Cu}(\mathrm{II})$ from the aqueous samples. The

Table 2. Analytical performance parameters (HF-SLPME) in the linear range of $0.01-20 \mu \mathrm{g} / \mathrm{mL}(\mathrm{n}=$ 5) at optimum condition.

\begin{tabular}{cccccc}
\hline & Equation & $\mathbf{R}^{2}$ & LOD $(\boldsymbol{\mu g} / \mathbf{m L})$ & LOQ $(\boldsymbol{\mu g} / \mathbf{m L})$ & RSD \% \\
\hline HNO $_{3}$ F-MWCNTs & $\mathrm{Y}=0.434 \mathrm{X}+0.0048$ & 0.9947 & 0.013 & 0.046 & 3.45 \\
NaClO F-MWCNTs & $\mathrm{Y}=0.04 \mathrm{X}+0.0052$ & 0.9977 & 0.015 & 0.05 & 3.99 \\
\hline
\end{tabular}

Table 3. Real sample analysis of an industrial effluent.

\begin{tabular}{cccc}
\hline Fiber Type & Observed Concentration $(\boldsymbol{\mu g} / \mathbf{m L})$ & RSD (\%) & RR \% $^{*}$ \\
\hline $\mathrm{HNO}_{3}$ F-MWCNTs & 0.25 & 7.2 & 97.86 \\
$\mathrm{NaClO}$ F-MWCNTs & 0.24 & 6.3 & 99.04 \\
\hline
\end{tabular}

* Relative recovery percent.

Table 4. Comparison of HF-LPME with some other extraction methods for determination of $\mathrm{Cu}^{2+}$ in the water solution samples.

\begin{tabular}{|c|c|c|c|}
\hline Method & EF & LOD $(\mu \mathrm{g} / \mathrm{L})$ & Ref \\
\hline DLLME ${ }^{*}$-FAAS & 48 & 0.003 & {$[40]$} \\
\hline SPE ${ }^{* *}$-FAAS (solid Phase: modified Amberlite) & 100 & 0.004 & {$[40]$} \\
\hline SPE-FAAS (Solid phase: modified silica gel) & 300 & 0.005 & {$[40]$} \\
\hline HF-MWCNTs- $\mathrm{HNO}_{3}$ & 446 & 0.013 & This work \\
\hline HF-MWCNTs-NaClO & 432 & 0.015 & This work \\
\hline
\end{tabular}

* Dispersive Liquid-Liquid Microextraction, ${ }^{* *}$ Solid-Phase Extraction. 
experimental setup is very simple and highly affordable. Among all microextraction techniques reported, this technique is one of the most effective sample preparation/pre-concentration techniques. The hollow fiber is disposable, so single use of microextraction device reduces the risk of cross-contamination and carry-over problems.

The proposed method allows very effective and enriched recuperation of ionic analyte into MWCNTs/organic phase. This procedure can be successfully used for the analysis of organic and inorganic analytes in the aqueous samples. Moreover, the method was applied to the analysis of environmental water samples giving good qualitative and quantitative results. Other advantages of this method are good repeatability, low limits of detection and \%RSD.

\section{References}

[1] González-Muñoz, M.J., Rodríguez, M.A., Luque, M. and Álvarez, J.R. (2006) Recovery of Heavy Metals from Metal Industry Waste Waters by Chemical Precipitation and Nanofiltration. Desalination, 200, 742-744. http://dx.doi.org/10.1016/j.desal.2006.03.498

[2] Kang, S.-Y., Lee, J.-U., Moon, S.-H. and Kim, K.-W. (2004) Competitive Adsorption Characteristics of $\mathrm{Co}^{2+}$, $\mathrm{Ni}^{2+}$, and $\mathrm{Cr}^{3+}$ by IRN-77 Cation Exchange Resin in Synthesized Wastewater. Chemosphere, 56, 141-147. http://dx.doi.org/10.1016/j.chemosphere.2004.02.004

[3] Fu, F. and Wang, Q. (2011) Removal of Heavy Metal Ions from Wastewaters: A Review. Journal of Environmental Management, 92, 407-418. http://dx.doi.org/10.1016/j.jenvman.2010.11.011

[4] Jha, M.K., Kumar, V., Jeong, J. and Lee, J.-C. (2012) Review on Solvent Extraction of Cadmium from Various Solutions. Hydrometallurgy, 111-112, 1-9. http://dx.doi.org/10.1016/j.hydromet.2011.09.001

[5] Dadfarnia, S., Shabani, A.-M. H. and Kamranzadeh, E. (2009) Separation/Preconcentration and Determination of Cadmium Ions by Solidification of Floating Organic Drop Microextraction and FI-AAS. Talanta, 79, 1061-1065.

http://dx.doi.org/10.1016/j.talanta.2009.02.004

[6] Mahugo-Santana, C., Sosa-Ferrera, Z., Torres-Padron, M. and Santana-Rodriguez, J.J. (2011) Application of New Approaches to Liquid-Phase Microextraction for the Determination of Emerging Pollutants. TrAC Trends in Analytical Chemistry, 30, 731-748.

[7] Lord, H. and Pawliszyn, J. (2000) Evolution of Solid-Phase Microextraction Technology. Journal of Chromatography A, 885, 153-193. http://dx.doi.org/10.1016/S0021-9673(00)00535-5

[8] Jeannot, M.A. and Cantwell, F.F. (1996) Solvent Microextraction into a Single Drop. Analytical Chemistry, 68, 2236-2240. http://dx.doi.org/10.1021/ac960042z

[9] Jeannot, M.A. and Cantwell, F.F. (1997) Mass Transfer Characteristics of Solvent Extraction into a Single Drop at the Tip of a Syringe Needle. Analytical Chemistry, 69, 235-239. http://dx.doi.org/10.1021/ac960814r

[10] Rasmussen, K.E. and Pedersen-Bjergaard, S. (2004) Developments in Hollow Fibre-Based, Liquid-Phase Microextraction. TrAC Trends in Analytical Chemistry, 23, 1-10.

[11] Pedersen-Bjergaard, S. and Rasmussen, K.E. (1999) Liquid-Liquid-Liquid Microextraction for Sample Preparation of Biological Fluids Prior to Capillary Electrophoresis. Analytical Chemistry, 71, 2650-2656. http://dx.doi.org/10.1021/ac990055n

[12] Zhu, L., Zhu, L. and Lee, H.K. (2001) Liquid-Liquid-Liquid Microextraction of Nitrophenols with a Hollow Fiber Membrane Prior to Capillary Liquid Chromatography. Journal of Chromatography A, 924, 407-414. http://dx.doi.org/10.1016/S0021-9673(01)00906-2

[13] Psillakis, E. and Kalogerakis, N. (2003) Developments in Liquid-Phase Microextraction. TrAC Trends in Analytical Chemistry, 22, 565-574.

[14] Ziagova, M., Kyriakou, G. and Liakopoulou-Kyriakides, M. (2009) Co-Metabolism of 2,4-Dichlorophenol and 4-Cl-mCresol in the Presence of Glucose as an Easily Assimilated Carbon Source by Staphylococcus xylosus. Journal of Hazardous Materials, 163, 383-390. http://dx.doi.org/10.1016/j.jhazmat.2008.06.102

[15] Desouky, O.A., Daher, A.M., Abdel-Monem, Y.K. and Galhoum, A.A. (2009) Liquid-Liquid Extraction of Yttrium Using Primene-JMT from Acidic Sulfate Solutions. Hydrometallurgy, 96, 313-317. http://dx.doi.org/10.1016/j.hydromet.2008.11.009

[16] De La Torre-Roche, R.J., Lee, W.Y. and Campos-Diaz, S.I. (2009) Soil-Borne Polycyclic Aromatic Hydrocarbons in El Paso, Texas: Analysis of a Potential Problem in the United States/Mexico Border Region. Journal of Hazardous Materials, 163, 946-958. http://dx.doi.org/10.1016/j.jhazmat.2008.07.089

[17] Tuzen, M., Saygi, K.O. and Soylak, M. (2008) Solid Phase Extraction of Heavy Metal Ions in Environmental Samples 
on Multiwalled Carbon Nanotubes. Journal of Hazardous Materials, 152, 632-639.

http://dx.doi.org/10.1016/j.jhazmat.2007.07.026

[18] Bhatnagar, A., Kumar, E. and Sillanpää, M. (2011) Fluoride Removal from Water by Adsorption-A Review. Chemical Engineering Journal, 171, 811-840. http://dx.doi.org/10.1016/j.cej.2011.05.028

[19] Rao, G.P., Lu, C. and Su, F.S. (2007) Sorption of Divalent Metal Ions from Aqueous Solution by Carbon Nanotubes: A Review. Separation and Purification Technology, 58, 224-231. http://dx.doi.org/10.1016/j.seppur.2006.12.006

[20] Lu, C. and Liu, C.T. (2006) Removal of Nickel(II) from Aqueous Solution by Carbon Nanotubes. Journal of Chemical Technology and Biotechnology, 81, 1932-1940. http://dx.doi.org/10.1002/jctb.1626

[21] Akhtar, N., Iqbal, J. and Iqbal, M. (2004) Removal and Recovery of Nickel(II) from Aqueous Solution by Loofa SpongeImmobilized Biomass of Chlorella sorokiniana: Characterization Studies. Journal of Hazardous Materials, 108, 85-94. http://dx.doi.org/10.1016/j.jhazmat.2004.01.002

[22] Lu, C. and Chiu, H. (2006) Adsorption of Zinc(II) from Water with Purified Carbon Nanotubes. Chemical Engineering Science, 61, 1138-1145. http://dx.doi.org/10.1016/j.ces.2005.08.007

[23] Es'haghi, Z. and Azmoodeh, R. (2010) Hollow Fiber Supported Liquid Membrane Microextraction of Cu ${ }^{2+} \mathrm{Followed}$ by Flame Atomic Absorption Spectroscopy Determination. Arabian Journal of Chemistry, 3, 21-26. http://dx.doi.org/10.1016/j.arabjc.2009.12.004

[24] Ho, T.S., Pedersen-Bjergaard, S. and Rasmussen, K.E. (2002) Recovery, Enrichment and Selectivity in Liquid-Phase Microextraction: Comparison with Conventional Liquid-Liquid Extraction. Journal of Chromatography A, 963, 3-17. http://dx.doi.org/10.1016/S0021-9673(02)00215-7

[25] Basheer, C., Alnedhary, A.A., Rao, B.S., Balasubramanian, R. and Lee, H.K. (2008) Ionic Liquid Supported ThreePhase Liquid-Liquid-Liquid Microextraction as a Sample Preparation Technique for Aliphatic and Aromatic Hydrocarbons Prior to Gas Chromatography-Mass Spectrometry. Journal of Chromatography A, 1210, 19-24. http://dx.doi.org/10.1016/j.chroma.2008.09.040

[26] Wu, C.H. (2007) Studies of the Equilibrium and Thermodynamics of the Adsorption of $\mathrm{Cu}^{2+}$ onto As-Produced and Modified Carbon Nanotubes. Journal of Colloid and Interface Science, 311, 338-346. http://dx.doi.org/10.1016/j.jcis.2007.02.077

[27] Tsai, Y.C. and Huang, J.D. (2006) Poly(Vinyl Alcohol)-Assisted Dispersion of Multiwalled Carbon Nanotubes in Aqueous Solution for Electroanalysis. Electrochemistry Communications, 8, 956-960. http://dx.doi.org/10.1016/j.elecom.2006.04.003

[28] Es’haghi, Z., Golsefidi, M.A., Saify, A., Tanha, A.A., Rezaeifar, Z. and Alian-Nezhadia, Z. (2010) Carbon Nanotube Reinforced Hollow Fiber Solid/Liquid Phase Microextraction: A Novel Extraction Technique for the Measurement of Caffeic Acid in Echinacea purpurea Herbal Extracts Combined with High-Performance Liquid Chromatography. Journal of Chromatography A, 1217, 2768-2775. http://dx.doi.org/10.1016/j.chroma.2010.02.054

[29] Es'haghi, Z. (2009) Determination of Widely Used Non-Steroidal Anti-Inflammatory Drugs in Water Samples by in Situ Derivatization, Continuous Hollow Fiber Liquid-Phase Microextraction and Gas Chromatography-Flame Ionization Detector. Analytica Chimica Acta, 641, 83-88. http://dx.doi.org/10.1016/j.aca.2009.03.043

[30] Sarafraz-Yazdi, A. and Es'haghi, Z. (2005) Two-Step Hollow Fiber-Based, Liquid-Phase Microextraction Combined with High-Performance Liquid Chromatography: A New Approach to Determination of Aromatic Amines in Water. Journal of Chromatography A, 1082, 136-142. http://dx.doi.org/10.1016/j.chroma.2005.05.102

[31] Basheer, C., Alnedhary, A.A., Rao, B.S., Balasubramanian, R. and Lee, H.K. (2008) Ionic Liquid Supported ThreePhase Liquid-Liquid-Liquid Microextraction as a Sample Preparation Technique for Aliphatic and Aromatic Hydrocarbons Prior to Gas Chromatography-Mass Spectrometry. Journal of Chromatography A, 1210, 19-24. http://dx.doi.org/10.1016/j.chroma.2008.09.040

[32] Pálmarsdóttir, S., Thordarson, E., Edholm, L.E., Jönsson, J.Å. and Mathiasson, L. (1997) Miniaturized Supported Liquid Membrane Device for Selective On-Line Enrichment of Basic Drugs in Plasma Combined with Capillary Zone Electrophoresis. Analytical Chemistry, 69, 1732-1737. http://dx.doi.org/10.1021/ac960668p

[33] Rubio, S. and Pérez-Bendito, D. (2003) Supra-Molecular Assemblies for Extracting Organic Compounds. TrAC Trends in Analytical Chemistry, 22, 470-485.

[34] Mukerjee, P. and Mysels, K.J. (1971) Critical Micelle Concentration of Aqueous Surfactant Systems. Vol. 36, US Government Printing Office, Washington DC.

[35] Sarafraz-Yazdi, A., Amiri, A.H. and Es'haghi, Z. (2008) BTEX Determination in Water Matrices Using HF-LPME with Gas Chromatography-Flame Ionization Detector. Chemosphere, 71, 671-676. http://dx.doi.org/10.1016/j.chemosphere.2007.10.073

[36] Es’haghi, Z., Khooni, M.A.K. and Heidari, T. (2011) Determination of Brilliant Green from Fish Pond Water Using Carbon Nanotube Assisted Pseudo-Stir Bar Solid/Liquid Microextraction Combined with UV-Vis Spectroscopy-Diode 
Array Detection. Spectrochimica Acta Part A, 79, 603-607. http://dx.doi.org/10.1016/j.saa.2011.03.042

[37] Pedersen-Bjergaard, S. and Rasmussen, K.E. (2008) Liquid-Phase Microextraction with Porous Hollow Fibers, a Miniaturized and Highly Flexible Format for Liquid-Liquid Extraction. Journal of Chromatography A, 1184, 132-142. http://dx.doi.org/10.1016/j.chroma.2007.08.088

[38] Shen, G. and Lee, H.K. (2002) Hollow Fiber-Protected Liquid-Phase Microextraction of Triazine Herbicides. Analytical Chemistry, 74, 648-654. http://dx.doi.org/10.1021/ac0105610

[39] Boyd-Boland, A.A. and Pawliszyn, J. (1995) Solid-Phase Microextraction of Nitrogen-Containing Herbicides. Journal of Chromatography A, 704, 163-172. http://dx.doi.org/10.1016/0021-9673(95)00151-C

[40] Farajzadeh, M.A., Bahram, M., Mehr, B.G. and Jonsson, J.A. (2008) Optimization of Dispersive Liquid-Liquid Microextraction of Copper (II) by Atomic Absorption Spectrometry as Its Oxinate Chelate: Application to Determination of Copper in Different Water Samples. Talanta, 75, 832-840. http://dx.doi.org/10.1016/j.talanta.2007.12.035 